\title{
Inclusion of Increased Air Turbulence Caused by Coke Production into Atmospheric Propagation Modelling
}

\author{
Jacek Żeliński ${ }^{1}$ (1) $\cdot$ Dorota Kaleta $^{2} \cdot$ Jolanta Telenga-Kopyczyńska² $^{2}$
}

Received: 8 February 2018/Revised: 30 June 2018/Accepted: 1 August 2018/Published online: 10 August 2018

(C) The Author(s) 2018

\begin{abstract}
Gaussian plume models are still used in cases where short-distance, routine calculations have to be done. They use universal parameters to parameterise the atmospheric-and earth-surface impact on the dispersion of air pollutants that can produce satisfactory results in overall conditions. This is not the case in the place-specific applications, when standard models do not reflect all of the mechanisms involved in local dispersion phenomena. This limitation applies in particular to atypical objects which are characterised by high thermal and mechanical turbulence being introduced into the air. Such places form locally distinctive air turbulence reflected by specific vertical wind speed profiles. Based on the knowledge of their shape, the turbulence and diffusion intensity information may be transferred to the propagation model. The analysis of the wind profiles measured in the vicinity of the big coking plant is presented in this paper. The wind profiles' exponent values which had been obtained on this basis were compared with the values used with standard models. Also, measured marker-gas concentrations have been related to values calculated with the use of the model equipped with modified exponents as well as to the values obtained from the traditional model.
\end{abstract}

Keywords Coke production - Gaussian plume models · Pollution dispersion modelling · Air turbulence $\cdot$ Wind profile exponents

\section{Introduction}

Gaussian plume models of the so-called old (or first) generation use parameters which characterise the influence of the atmosphere and the earth-surface on the intensity of pollutant dispersion, using universal values of empirical origin. In such models, the ability to generate mechanical turbulence by terrain surface is described by the surface roughness coefficient $z 0$, while the power-law (or meteorological) exponent $p$ constitutes a measure of both thermal

Jacek Żeliński

jzelinski@ichpw.pl

Dorota Kaleta

dorota.kaleta@polsl.pl

Jolanta Telenga-Kopyczyńska

jtelenga@ichpw.pl

1 Institute for Chemical Processing of Coal, Zamkowa 1, 41-803 Zabrze, Poland

2 Department of Air Protection, Silesian University of Technology, Konarskiego 22B, 44-100 Gliwice, Poland and mechanical turbulences (El-Harbawi 2013; Saha 2008; Zanetti 1990). Parameterisation of the atmosphere due to thermal turbulence consists in determining atmospheric stability and introducing the right value of the exponent $p$ into a model. The $p$ value is chosen from the set comprising values specific for subsequent atmosphere stability classes (mainly conforming to Pasquill-Gifford stability categories). In this way, the exponent $p$ becomes a parameter formally describing the thermal turbulence. In many models, this exponent also contains a component of mechanical turbulence, which is usually taken into account using different sets of exponential values for different types of land (typically, urban and rural) (Turner 1994; EPA 1995).

In specific applications, the standard values of the meteorological exponent do not reflect, in a fully representative way, the mechanisms of atmospheric dispersion. This is confirmed by the observation that anthropogenic factors that excel the normal parameter levels which determine the atmospheric stability might overcome the natural dispersion mechanisms. This observation is true for 
industrial objects (José et al. 2004). This applies in particular to non-typical objects, such as a coke oven battery, which is a low-stack emission source (about $10 \mathrm{~m}$ high) with heat emission of up to about $3 \mathrm{~kW} / \mathrm{m}^{2}$ (own estimations). This is significantly more than the yearly averaged heat emission from the earth surface, which creates thermal turbulence in the atmosphere (in the Central Europe zone, this emission reaches $100-130 \mathrm{~W} / \mathrm{m}^{2}$ ) (National Research Council 1977; Madany 1996). Despite the generally small area of industrial objects that emit heat, the large unitary emission and the mechanical impact on the flow forced by industrial buildings and installations (Zaïdi et al. 2014) may result in increased or above-average turbulence in their immediate vicinity. This has been confirmed both in measurement (Huq and Franzese 2012) and numerical (Lateb et al. 2010; Mirzaei and Carmeliet 2013; Xie et al. 2013) experiments.

The impact of heat emission on atmospheric dispersion has been a subject of research for years, focusing primarily on the phenomenon of the 'heat island'. It is commonly observed in larger cities-irrespective of the climate zone in which they are located-and consists of local modifications of the atmosphere characteristics caused by the shape and properties of the earth's surface and the significant emission of heat, moisture and air pollution. The work on the phenomenon of heat islands was initiated in the 1970s (Garstang et al. 1975) and intensively conducted in the subsequent years (Oke 1981; Landsberg 1981). As a result, the main types of heat islands have been defined, and their basic structures of varying ranges and character have been recognised and categorised into the urban canopy and the urban boundary layer. Furthermore, essential features of the heat island area have been identified. Among them, the following can be distinguished: the maintenance of slightly stable or even neutral atmospheric stability directly above the city area in night conditions up to several hundred metres (typical height is about 100-300 m) (Tapper 1990); the occurrence of significantly elevated air temperature in the area (Oke 1995); the formation of an 'urban plume' of warm air on the leeward side of the city (starting from the outskirts of the urban areas) (Landsberg 1981; Oke 1995); the tendency to change the vertical air temperature profile towards the shape characteristic for neutral stratification, combined with local turbulence creation (Glazier et al. 1976; Godowitch et al. 1985); the frequent formation of elevated inversion over the heat island (Uno et al. 1992); the formation of HIC (Heat Island Circulation) system under weak winds (Ado 1992); and the disappearance of the heat island with an increase of the vertical mixing intensity, at the same time, under winds of higher speed (Draxler 1986; Hildebrand and Ackerman 1984).
The extent of the heat island, defined by the difference between the temperature of the air inside and outside the island (in relation to non-urban areas), can be estimated to be several dozen kilometres from the city outskirts on its leeward side. For example, in the well-known St. Louis experiment, a $40 \mathrm{~km}$ long heat island was recorded on the leeward side of the city, formed by an air layer in which the temperature was elevated by $1.5^{\circ} \mathrm{C}$, extending from the earth surface up to the height of about 1 kilometre (Auer 1981).

Another phenomenon recorded in urban and industrial areas that influences dispersion in the atmosphere is the mechanical interaction of objects of considerable dimensions and air flows. Each object encircled by the moving mass of air leaves a 'trace' in the form of an increased turbulence path generated mechanically-and, if it emits heat, also thermally (Carpentieri 2012). From the time when atmospheric turbulence measurements were initiated, the turbulence dependence of the nature and character of the areas over which the air masses moved before reaching the measurement point was observed (Panofsky et al. 1977). Observations of this type were made in hilly or mountainous areas as well as over large water reservoirs. This effect is especially visible near lakes and other inland water bodies. Due to the low surface roughness, high heatstorage capacity and thermal inertia of water, the height of the inner boundary layer above the water surface is limited and characterised by small turbulence (Madany 1996). This turbulence of limited energy is conveyed inland along the mean velocity vectors of the wind (Panofsky et al. 1982). Similar studies were conducted in marshy areas (Walter et al. 2011). Analogical measurements at city boundaries and on flat areas with no significant terrain obstacles are described in Högström et al. (1982). In this work, results, analysis and comparisons of the wind speed measurements made in the city's centre and beyond at two different altitudes are presented.

In all of the above-mentioned papers, the authors indicated that the spectra of horizontal variations of wind components were strongly dependent on the geomorphological conditions of the terrain and on the windward side of the points at which the measurements were made. Moreover, it was found that the described tendency, manifested in the existence of 'memory', collecting effects of components influencing the flow in the form of proper turbulence level, is clearly evident in the low-frequency spectra of turbulence. In the high-frequency range, this tendency is weak - the spectra of component velocity variances show a short time in which they adjust their values to the nature of the surface over which the flow takes place in the moment. The described behaviour is referred to by the term 'spectral lag' (Högström et al. 1982). Low-frequency turbulence, deviating from values 
characteristic for local geomorphological conditions due to the influence of distant sources of turbulence lying on the windward side of the measuring point, was also described in other works. Terrain shape (Andreas 1987; Smeets et al. 1998), disturbances associated with conditions which are formed at the border of convective boundary layer (McNaughton and Laubacg 2000), or both (Li et al. 2007), are indicated as sources of turbulence.

In the case of industrial objects, the factors mentioned above result in increased dynamics of pollutant dispersion in the atmosphere, which in turn are reflected in reduced concentrations. Another effect is the extended accuracy of concentrations estimated using simple box models, working under the assumption of evenly distributed vertical concentrations of pollutants (Hanna and Baja 2009).

In addition, the distance over which the modified turbulence remains is also important. In the US EPA guidelines for air quality modelling (EPA 2000), this distance, which extends from the source of the disturbance to a place where the increased turbulent atmospheric characteristics can still be observed, is defined as 3 kilometres. The AERMET meteorological pre-processor also defines 3 kilometres as the distance over which to evaluate the effects that earth-surface parameters, such as albedo, Bowen number and surface roughness, have on turbulence. Estimates of this type are designed to incorporate modified dispersion conditions into dispersion calculations, particularly for urban and industrial areas. Other studies (EPA 2000, 2004; Paine and Egan 1987) also point to the spatial variations in air turbulence that develop in the boundary layer along the wind direction, forced by changes in earthsurface characteristics and heat emissions. For areas with high roughness accompanied by significant heat emissions leading to the reduction of atmospheric stability (which is characteristic for coking plants), it is indicated that the creation length of characteristic flow turbulence may be considerably shorter than 3 kilometres (Smedman-Högström and Högström 1978).

Differences in the formation of air turbulence and the mixing height under the influence of varying thermal and mechanical surface effects are evident in empirical observations (Tapper 1990) in atmospheric boundary layer investigations (Gryning and Batchvarova 2007) and in numerical simulations (Lateb et al. 2010). These differences are reflected in the 'urban' and 'rural' meteorological exponent values of traditional Gaussian models, the first of which contains the information about additional turbulence associated primarily with differences in the shortwave solar heat accumulated in the urban area and beyond. These differences are, for example, clearly visible in almost identical exponent values $(\sim 0.15)$ expressing moderately unstable atmosphere (B) in urban conditions and neutral stability (D) in non-urban conditions (Turner 1994; EPA
1995). Experimental studies show that modified dispersion parameters have to be taken into account both in Gaussian (Huq and Franzese 2012) and more complex models (Batchvarova and Gryning 2005; Carpentieri et al. 2012). While talking about increased air turbulence, other relevant phenomena can also be pointed out (Wang et al. 2017a, b).

In the present paper, the estimations of meteorological exponent values were done on the basis of vertical wind profiles, the shape of which in the planetary boundary layer-as well as the respective $p$ values-relates to atmospheric turbulence (Saha 2008) and is influenced thermally and mechanically by large industrial objects. The analysis of these wind profiles allows for the assessment of locally occurring atmospheric turbulence in the vicinity of such subjects (EPA 2000). Valuations of this kind were conducted for one of the Polish coking plants.

\section{Methods and Site Description}

At the base of the presented information, the fundamental assumption has been made that air masses moving along a wind direction were characterised by turbulence reflecting the characteristics of the objects over which the flow had occurred, especially in a range of lower frequencies. This tendency should be confirmed by the directional analysis of turbulence. The value of the meteorological exponent $p$ was adopted as a measure of turbulence (EPA 2000). This value was evaluated on the basis of the vertical wind profile, by measuring wind velocity $u_{1}$ and $u_{2}$ at two heights $\left(h_{1}=2 \mathrm{~m}\right.$ and $\left.h_{2}=10 \mathrm{~m}\right)$ using a meteorological tower located in the area neighbouring the coking plant, which was about $600 \mathrm{~m}$ southwest from its strongest heat source. This source was the coke oven batteries (azimuth: coke oven batteries-meteorological tower was $195^{\circ}$ ) and about $280 \mathrm{~m}$ (in the same direction) from the nearest byproduct installation. The location of the meteorological tower is shown in Fig. 1.

As the measurement tool, the meteorological station AsterMet (Kraków, Poland) has been used (Fig. 2). It consisted of a set of basic sensors, containing 2 vane anemometers W-104 placed at the 2 and $10 \mathrm{~m}$ height, with the following characteristics:

wind direction measurement range $0 / 360^{\circ}$, wind direction measurement resolution $1^{\circ}$, wind speed measurement range wind speed measurement resolution $0 / 60 \mathrm{~m} / \mathrm{s}$, wind speed measurement threshold $0.1 \mathrm{~m} / \mathrm{s}$, $0.4 \mathrm{~m} / \mathrm{s}$.

And two temperature sensors Pt100 in anti-radiant shields, placed at the same height with the characteristics: temperature measurement range $\quad-40 /+60{ }^{\circ} \mathrm{C}$, 
Fig. 1 The location of the meteorological tower and coke oven batteries

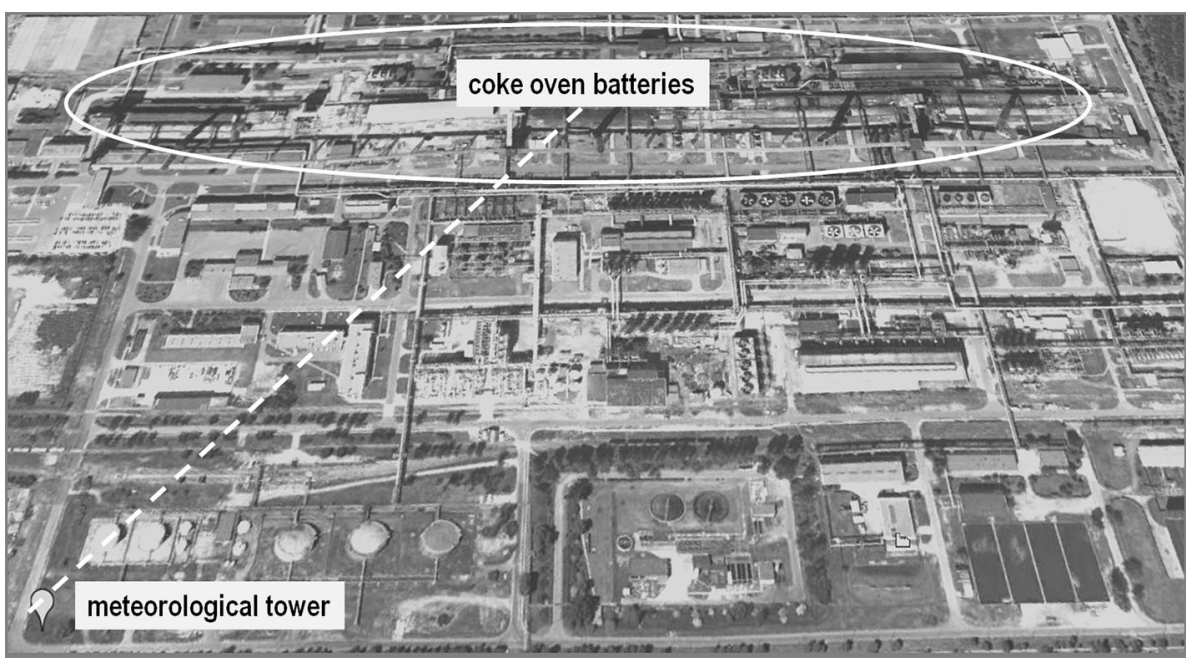

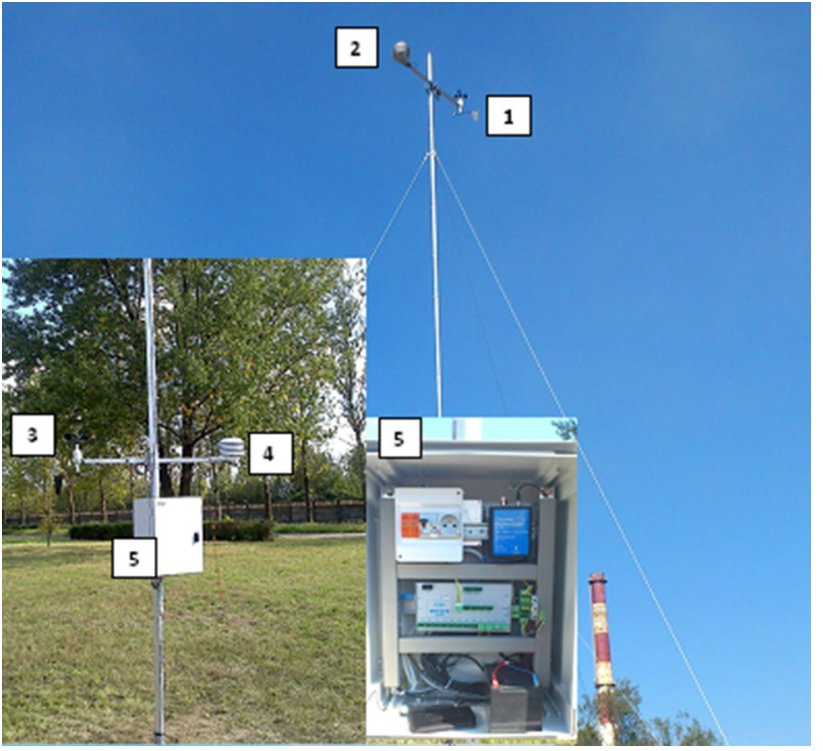

Fig. 2 Meteorological tower AsterMet: 1-vane anemometer W-104 (height $10 \mathrm{~m}$ ), 2-temperature sensor Pt100 (height $10 \mathrm{~m}$ ), 3-vane anemometer W-104 (height $2 \mathrm{~m}$ ), 4-temperature sensor Pt100 (height $2 \mathrm{~m}$ ), 5-logger SM-076

temperature measurement accuracy $\pm 0.1{ }^{\circ} \mathrm{C}$

The SM-076 logger, also placed on the mast, performed three basic functions: processing of measurement signals, transmission of the data in a given time regime via., a connected GSM transmission link and data collection and archiving. With a sampling frequency of 1 second, the SM076 measured mid- and low-frequency components of wind direction and speed.

In addition, the AsterMet tower has been equipped with a protection system from atmospheric discharges and electrical interference, both from the power supply and transmission.
More than 52,000 wind profiles were taken into account when estimating the value of the $p$ parameter, of which about 32,200 profiles were analysed after discarding erroneous or high uncertainty values. We have obtained approximately 430 profiles for the extremely unstable class (A), 2800 profiles for the moderately unstable class (B), 3160 profiles for the slightly unstable class (C), 16,450 profiles for the class of neutral stability (D), 4620 for the slightly stable class (E) and 3700 profiles for the moderately stable class (F).

For each profile, a corresponding $p$ was assigned on the basis of the exponential wind profile formula (EPA 2000):

$\frac{u_{1}}{u_{2}}=\left(\frac{h_{1}}{h_{2}}\right)^{p}$

Individual values of the exponent $p$ were assigned to the stability classes appearing in the time of profile measurements. Stability evaluations were made using the Solar Radiation Delta-T (EPA 1994) method, on the basis of wind speed measured at a height of $10 \mathrm{~m}$, along with the vertical temperature gradient and the solar radiation. Both were recorded at the nearby regular meteorological station between October 2012 and 2013. In this way 6 sets of $p$ values corresponding to the standardised stabilities of the atmosphere were obtained.

Next, a directional analysis of turbulence was performed. For this goal, each set of $p$ values was divided into two subsets due to the direction of the wind. The first contains observations made while the wind direction was in the range of $330^{\circ}-60^{\circ}$, comprising airflow from above the coke oven batteries [these winds were marked as north $(\mathrm{N})$ ]. The black dashed line in Fig. 1 indicates the secant of this angle traversing the point of the meteorological tower location. The approximate location of the coke oven batteries is indicated by an ellipse on the same figure. The second subset of $p$ values includes measurements related to 
the remaining directions of airflow (winds marked as WSE with corresponding secant azimuths: $105^{\circ} ; 195^{\circ} ; 285^{\circ}$ ). In total, 12 medians of $p$ calculated from the vertical wind profiles for each of 6 standardized stability classes and 2 wind directions ( $\mathrm{N}$ and WSE) were taken as the final values of the $p$ exponents. The selection of a median, instead of mean, as a function which should serve to calculate the expected value of the exponent $p$ was made to decrease the influence of the values laying beyond the borders of adjacent stability classes.

To investigate the influence of newly-developed exponents for the correctness of calculated concentrations, the field experiment has been undertaken. Thoroughly controlled, one-point marker gas $\left(\mathrm{SF}_{6}\right)$ emissions were arranged in a central place of the mid-coke oven battery. In the same time, with the appropriate delay, marker gas 20-min concentrations have been measured on arcs consisting of a few reception points (usually 4-7) spread perpendicularly to the wind direction, located on the borders of the coking plant under investigation. Also, the most important meteorological data have been measured (wind speed and direction, air temperature and solar radiation). On the basis of the newly calculated exponents, $\mathrm{SF}_{6}$ concentration calculations were done in these receptors, with the use of arranged emissions and measured meteorological data. Evaluations of concentrations with the use of standard Polish Gaussian dispersion model (Polish Ministry of Environment 2010) have been made in the same points as well. In such a way, 24 sets of measured and double-calculated concentrations have been obtained. On this basis, the normalised mean squared error (NMSE) has been evaluated as an overall measure of bias and scatter (Eq. 2).

$\mathrm{NMSE}=\frac{\left(\overline{C_{\mathrm{o}}-C_{\mathrm{m}}}\right)^{2}}{\bar{C}_{\mathrm{o}} \cdot \bar{C}_{\mathrm{m}}}$

where, $C_{\mathrm{o}}, C_{\mathrm{m}}$-concentration observed and modelled.

\section{Results}

After the $p$ values had been obtained, basic statistical parameters such as probe abundance $(\mathrm{Ab})$, mean, standard deviation (SD), median (Me) and range of variation were calculated. They are shown in Table 1.

In the next step, tests were carried out to confirm that the differences between $p$ values for the $\mathrm{N}$ and WSE directions were statistically significant for each stability class. Firstly, using the Shapiro-Wilk test, it was examined whether the variables in question exhibited normal distribution, assuming significance level $\alpha=0.05$. Shapiro-Wilk test results show $(P<\alpha)$ that in each case, regardless of wind direction and atmospheric stability class, the distribution of samples is not normal (Table 2).

Due to the lack of distribution normality, the MannWhitney nonparametric test was used to determine the significance of the differences between the values of the exponent corresponding to the $\mathrm{N}$ and WSE winds, separately for each exponent from the six atmospheric stability classes. The analysis was performed at the same assumed significance level $\alpha=0.05$. The results of the test showed that the significant differences between the values of the exponent $p$ occurred in stability classes $\mathrm{B} / \mathrm{F}$, with the greatest difference noted for stability $\mathrm{F}$ (Table 3 ). In the case of class A, there are no statistically significant differences between the values of the exponent $p$ noted for the airflow from the side of the coke oven battery and other directions $(P>\alpha)$.

All statistical analyses were performed using the Statistica EN v. 12 software package.

To evaluate the behaviour of the modified exponents in atmospheric dispersion modelling, every set of $\mathrm{SF}_{6}$ concentrations observed during measurements were compared to corresponding values calculated with use of the model equipped with modified exponents. The exemplary distribution shapes of these concentrations on measurement arcs are shown in the Fig. 3. (the case of the highest compliance between measurements and calculations with the use of modified exponents obtained for atmosphere stability D and wind speed $1.7 \mathrm{~m} / \mathrm{s}$ ) and Fig. 4 (the lowest compliance obtained for atmosphere stability B and wind speed $1.1 \mathrm{~m} /$ s). For comparison, distribution shapes of concentrations calculated with Polish standard model are also presented.

Also, the NMSE was calculated for the model with modified exponents and adjusted emission height (Żeliński et al. 2016). The NMSE value of 8.83 has been found.

\section{Discussion}

The present work has confirmed the influence of large industrial objects on the flow of air masses. It was demonstrated, using statistical methods, that for a coking plant this effect is reflected by the value of the exponent $p$ calculated from wind profiles. It has been observed on the basis of measurement analyses that, for low atmospheric stability classes (especially A, but also B) corresponding to high atmospheric turbulence caused by intensive solar heat, the values of measured exponents for opposed wind directions (N and WSE) are similar (Table 3). This indicates a slight effect of technological heat on atmospheric turbulence, or its lack. For stability class A this lack of influence is confirmed by the Mann-Whitney test of exponent equality, revealing a level of significance greater 
Table 1 Basic parameters of descriptive statistics

\begin{tabular}{llcll}
\hline Atmosphere stability classification & $\mathrm{Ab}$ & Mean $\pm \mathrm{SD}$ & $\mathrm{Me}$ & Range \\
\hline Wind direction inside the angle $330^{\circ}-60^{\circ}$ (wind $\left.N\right)$ & & & \\
$\mathrm{A}$ & 37 & $0.156 \pm 0.073$ & 0.163 & $0.000-0.317$ \\
$\mathrm{~B}$ & 272 & $0.214 \pm 0.181$ & 0.179 & $0.000-1.544$ \\
$\mathrm{C}$ & 540 & $0.183 \pm 0.065$ & 0.172 & $0.025-0.461$ \\
$\mathrm{D}$ & 3479 & $0.198 \pm 0.101$ & 0.179 & $0.000-1.639$ \\
$\mathrm{E}$ & 759 & $0.245 \pm 0.124$ & 0.222 & $0.034-1.365$ \\
$\mathrm{~F}$ & 983 & $0.308 \pm 0.216$ & 0.252 & $0.000-1.639$ \\
Wind direction outside the angle $330^{\circ}-60^{\circ}$ (wind WSE) & & & \\
$\mathrm{A}$ & 388 & $0.187 \pm 0.104$ & 0.179 & $0.000-0.468$ \\
$\mathrm{~B}$ & 2505 & $0.256 \pm 0.175$ & 0.216 & $0.000-1.489$ \\
$\mathrm{C}$ & 2623 & $0.231 \pm 0.106$ & 0.218 & $0.000-1.238$ \\
$\mathrm{D}$ & 12970 & $0.269 \pm 0.186$ & 0.225 & $0.000-2.622$ \\
$\mathrm{E}$ & 3862 & $0.374 \pm 0.281$ & 0.298 & $0.000-1.639$ \\
$\mathrm{~F}$ & 2746 & $0.518 \pm 0.363$ & 0.431 & $0.000-1.683$ \\
\hline
\end{tabular}

Table 2 Values of $\mathrm{W}$ statistics and calculated level of significance $P$ for the ShapiroWilk test of the $p$ exponents for the analysed wind directions and the subsequent classes of atmospheric stability, assuming $\alpha=0.05$

Table 3 Values of obtained $p$ medians and results of the Mann-Whitney test for the analysed wind directions in subsequent atmospheric stability classes, assuming $\alpha=0.05$

\begin{tabular}{llllll}
\hline Atmosphere stability class & $W$ & & $P$ & \\
\cline { 2 - 3 } \cline { 5 - 6 } & Wind N & Wind WSE & & Wind N & Wind WSE \\
\hline A & 0.937 & 0.983 & & 0.039 & 0.001 \\
B & 0.648 & 0.814 & & $\sim 0.000$ & $\sim 0.000$ \\
C & 0.963 & 0.948 & & $\sim 0.000$ & $\sim 0.000$ \\
D & 0.721 & 0.948 & & $\sim 0.000$ & $\sim 0.000$ \\
E & 0.681 & 0.807 & & $\sim 0.000$ & $\sim 0.000$ \\
F & 0.776 & 0.896 & & $\sim 0.000$ & $\sim 0.000$ \\
\hline
\end{tabular}

$W$-values of $W$ statistics for the Shapiro-Wilk test

$P$-calculated level of significance

\begin{tabular}{llllllc}
\hline Wind direction & \multicolumn{6}{l}{ Median $(\mathrm{Me})$} \\
\cline { 2 - 7 } & $\mathrm{A}$ & $\mathrm{B}$ & $\mathrm{C}$ & $\mathrm{D}$ & $\mathrm{E}$ & $\mathrm{F}$ \\
\hline Wind N & 0.163 & 0.179 & 0.172 & 0.179 & 0.222 & 0.252 \\
Wind WSE & 0.179 & 0.216 & 0.218 & 0.225 & 0.298 & 0.431 \\
$\mathrm{P}$ & 0.1238 & 0.0002 & $\sim 0.0000$ & $\sim 0.0000$ & $\sim 0.0000$ & $\sim 0.0000$ \\
Differences are valid & No & Yes & Yes & Yes & Yes & Yes \\
\hline
\end{tabular}

P-calculated level of significance for the Mann-Whitney test than the assumed value of $\alpha=0.05$. On the contrary, for the stable stability classes of the atmosphere (E and F), due to the limited inflow of solar heat, the impact of the technological heat becomes significantly higher. This is revealed by big differences in the exponent values for the $\mathrm{N}$ and WSE winds as well as in the near-zero values of the calculated significance level. For stabilities B-D this trend is preserved, with smaller differences.

Studies have confirmed that the value of the exponent $p$ increases with the decrease in natural atmospheric turbulence (as stability A moves towards stability E), which reflects the usual behaviour. However, in the case of air inflowing from the coke oven-side ( $\mathrm{N}$ wind), the value of this exponent does not change as much as in the case of inflow from other directions (tab. 3). The existence of this trend is also confirmed by standard deviations (Table 1), which in case of $\mathrm{N}$ winds attain lower values. For comparison, Table 4 contains values of the universal (ascribed to all terrain conditions) exponent $p$ used in the Polish standard dispersion model and the corresponding values of the 'urban' exponent widely used in other Gaussian models for calculations in urban territories (and thus areas with 
Fig. 3 The concentrations distribution with the highest compliance between measurements and calculations based on modified exponents

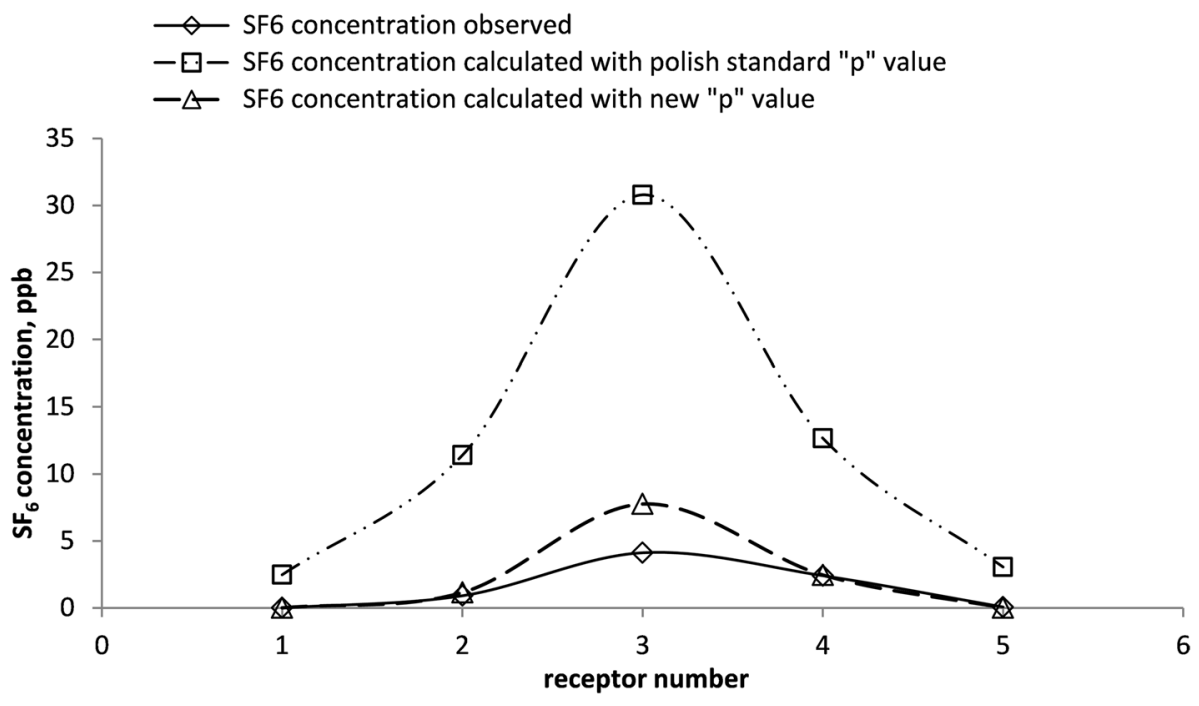

Fig. 4 The concentrations distribution with the lowest compliance between measurements and calculations based on modified exponents

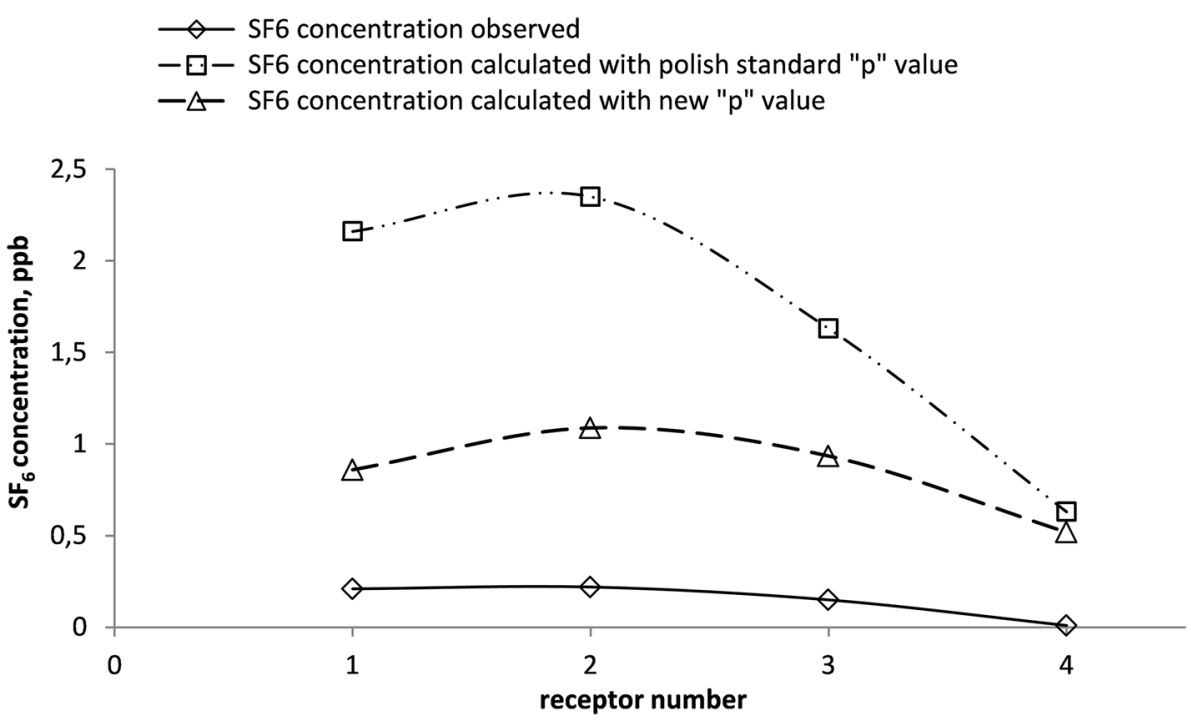

Table 4 Values of the exponent $p$ for each stability class

\begin{tabular}{lllllll}
\hline Exponent $p$ & \multicolumn{6}{l}{ Stability class } \\
\cline { 2 - 7 } & $\mathrm{A}$ & $\mathrm{B}$ & $\mathrm{C}$ & $\mathrm{D}$ & $\mathrm{E}$ & $\mathrm{F}$ \\
\hline Polish standard & 0.08 & 0.143 & 0.196 & 0.27 & 0.363 & 0.44 \\
Urban & 0.15 & 0.15 & 0.20 & 0.25 & 0.30 & 0.30 \\
\hline
\end{tabular}

thermally- and mechanically-induced above-average turbulence) (EPA 2015; Schulman and Scire 1980).

The values presented in the table are also shown on the chart (Fig. 5) with appropriate trend lines added to illustrate increments and to compare value trends of the different types of exponent. To obtain the trend line, the exponential regression that best describes the standard values of the exponent $p$ has been used.
Described relationships between exponent values for individual stability classes are shown in the box and whisker graph revealing the characteristics of the $p$ distribution (Fig. 6).

The relatively narrow gap and smaller interquartile range between the 10th and 90th percentile for the $\mathrm{N}$ winds indicate the more regular character of the flow from this direction, which is the result of turbulence from locally interacting technological sources (Batchvarova and Gryning 2005; Gousseau et al. 2011). Their influence consists in overlapping meteorological parameters of a stochastic nature by local effects constant in time, affecting air flow in the lower atmosphere (Landsberg 1981; Blocken et al. 2008), which limits the element of stochasticity formed by thermally and morphologically differentiated areas surrounding the coking plant. The impact of the plant is also reflected in the box and whisker graph (Fig. 6), particularly 
Fig. 5 Values of individual exponents $p$ and corresponding trend lines

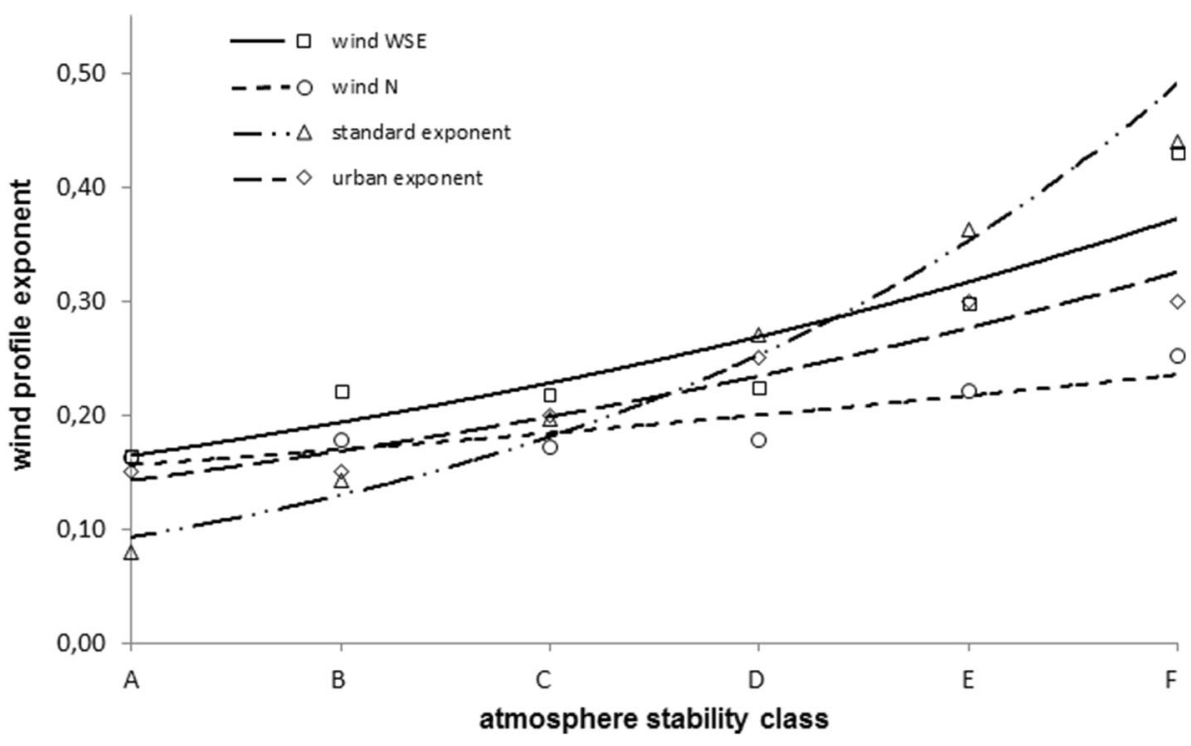

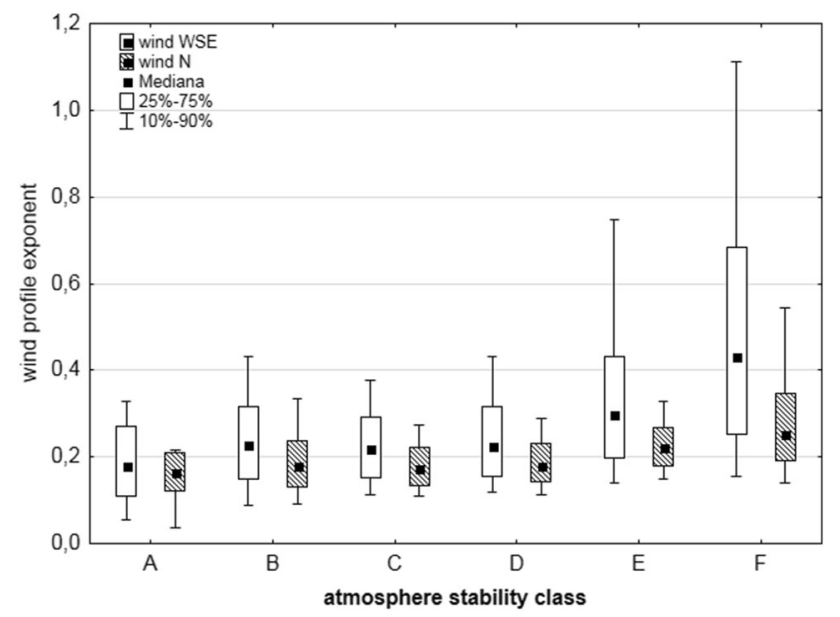

Fig. 6 Characteristics of the exponents $p$ distribution obtained in the measurements; $25-75 \%$ and $10-90 \%$ means ranges containing, respectively $50 \%$ (interquartile range) and $80 \%$ of exponent values

for the stability classes $\mathrm{E}$ and $\mathrm{F}$. It is revealed by significant differences in the upper percentiles and upper quartiles calculated for the $\mathrm{N}$ and WSE wind directions. These parameters correspond to the low-air turbulence in each stability class. As a consequence, there is also a smaller gap between the 10th and 90th percentile and a smaller interquartile range for the $\mathrm{N}$ direction in comparison to WSE winds. On the contrary, the differences between the lowest percentiles and the lowest quartiles noted for the $\mathrm{N}$ and WSE directions, which correspond to high-air turbulence in each stability class, are significantly smaller in all stability classes. This reflects the overall lower share of coking plants in turbulence when the natural turbulence level is raised.

The meteorological exponents obtained in the measurements were compared with their two counterparts. The first of them is used in the standard, universal Polish dispersion model, the second one in Gaussian models employed for computations in urban conditions (EPA 1995; Moussiopoulos 1997). In the first, standard exponent values for B and C stability classes are similar to the values obtained in measurements with the $\mathrm{N}$ winds. In other cases, significant differences in the values of the corresponding exponents are noted, as for stability class A, the standard exponent is lower, whilst for neutral and stable stability (classes D-F) it is higher for both N and WSE winds.

In turn, the exponents obtained for WSE winds are similar in trend and value to urban exponents, except for classes $\mathrm{B}$ and $\mathrm{F}$ (which may be due to the duplication of city exponent values from $\mathrm{A}$ to $\mathrm{B}$ and also from $\mathrm{E}$ to $\mathrm{F}$; see Table 4).

It is also worth pointing out the frequency of particular stability class occurrences in the investigated time interval. The class represented by the greatest number of occurrences in this period was neutral stability (D), whilst the smallest one was class A. Classes E and F, which cause the greatest impact of coking processes on the environment, are characterised by the second and third largest number of occurrences. This implies the need of using measured-and thus more accurate-exponent values particularly in these two classes, to increase the overall reliability of impact analysis that utilises long-period calculations in which values of $p$ are used.

The analysis of concentrations observed and calculated with the use of traditional and modified exponents reveals the far better behaviour of models incorporating latter ones. It is visible in each of the 24 comparisons between concentrations measured and calculated with-and without modified exponents. All refer to different meteorological conditions but each of them shows more accurate (to a 
Table 5 NMSE values calculated for four popular models

\begin{tabular}{lcll}
\hline Model & \multicolumn{2}{l}{ Experiment } & \\
\cline { 2 - 4 } & Prairie & EPRI & KPRI \\
& Grass & Kincaid & Indianapolis \\
\hline ADMS & $1117^{\mathrm{b}}$ & Not completed & Not completed \\
AERMOD & 1144 & 0400 & 0368 \\
HPDM & $6676^{*}$ & $0298^{\mathrm{b}}$ & $0341^{\mathrm{b}}$ \\
ISC3 & $4581^{*}$ & $1652^{*}$ & 0479 \\
\hline
\end{tabular}

An asterisk (*) indicates that the value is significantly different with $90 \%$ confidence from the base model, which is indicated with a "b". ADMS results are for 25 regimes, excluding the most stable stability groupings

greater or smaller extent) result of calculations while using modified exponents. This is also visible both for the best matching concentrations distributions (Fig. 3) and for distributions shown in Fig. 4 referring to the worst result obtained. The analysis of concentrations reveals also a specific character of modelling errors-the common overestimation of modelled values over observed-however, clearly smaller in a case of the model using modified exponents.

The modelling precision achieved in applying the adjusted model were compared with other popular models' results, namely ADMS 3.1, AERMOD (version 01247), HPDM (version 4.3, level 920605), and ISCST3 (version 00101). These models were examined by Irwin (Irwin et al. Irwin et al. 2002) with the use of tracer field data from three studies: Prairie Grass (tracer $\mathrm{SO}_{2}$ ), Kincaid (tracer $\mathrm{SF}_{6}$ ) and Indianapolis (tracer $\mathrm{SF}_{6}$ ), due to the models' performance to simulate average centerline concentration values. NMSE values calculated by Irwin for these models are presented in Table 5.

As it was mentioned, NMSE calculated for the standard Polish dispersion model adjusted to the conditions of the investigated coking plant yields 8.83. It is quite close to the level presented by other popular models (at least for the Prairie Grass data), although apparently two of them (ADMS, AERMOD) belonging to the class of the "next" generation plume models, are consistently better. This result is certainly influenced by the fact that vital meteorological measurements, as twice-daily NWS upper-air observations, were not incorporated into modelling with the adjusted model, which makes a characterization of the meteorological conditions for the tracer dispersion site less precise and means the deterioration of the overall model performance. The measurement had also been made outside the centerline of the plume which certainly influenced the final NMSE value while compare to presented data. Taking into consideration that without presented adjustments the same model makes calculations for the same object with NMSE value yielding 56.65 , one can say that changes made in meteorological exponents have vastly improved model performance. It is worth to emphasise that the model with presented adjustments is suitable to be used only for the object, for which it was created or similar.

\section{Conclusions}

- The presented measurements and observations reveal significant differences in the value of the exponent $p$ established for winds $\mathrm{N}$ and for other wind directions, which reflects the thermal and mechanical impact from the coke oven battery and other technological sources, on the overall air turbulence.

- Clearly, the lower values of meteorological exponents obtained from our measurements in comparison to the ones commonly used for stable stability-at which pollution concentration maxima for low industrial sources appear-lead to the conclusion that maximum concentrations calculated for such sources with traditional Gaussian dispersion models tend to be overestimated. This is confirmed by the results of $\mathrm{SF}_{6}$ measurements.

- High-frequency occurrences of neutral stability, characterised by lower exponent values than are commonly in use, should lead in calculations to a reduction in the calculated annual averages of concentration and dust deposition, below the level obtained with traditional models.

- The values of the Polish standard exponents, used for a case of industrial object characterised by the high emission of heat, are not only too high for the stable and neutral stability classes, but are also too low for the extremely unstable classes.

Acknowledgements The paper has been prepared within the framework of the project no. POIG.01.01.02-24-017/08 'Smart Coke Plant Meeting the Requirements of Best Available Techniques' co-financed by the European Regional Development Fund (ERDF). The results presented in this paper were obtained during the research project entitled „Monitorowanie uregulowań prawnych i wspólnotowych oraz działania wspierające samorządy oraz przemysł w zakresie ochrony środowiska" (IChPW No 11.18.008), financed by the Polish Ministry of Science and Higher Education.

\section{Compliance with ethical standards}

Conflict of interest statement On behalf of all authors, the corresponding author states that there is no conflict of interest.

Open Access This article is distributed under the terms of the Creative Commons Attribution 4.0 International License (http://creative commons.org/licenses/by/4.0/), which permits unrestricted use, 
distribution, and reproduction in any medium, provided you give appropriate credit to the original author(s) and the source, provide a link to the Creative Commons license, and indicate if changes were made.

\section{References}

Ado HY (1992) Numerical study of the daytime urban effect and its interaction with the Sea Breeze. J Appl Meteorol 31:1146-1164. https://doi.org/10.1175/1520-0450(1992)031\%3c1146: NSOTDU\%3e2.0.CO;2

Andreas EL (1987) Spectral measurements in a disturbed boundary layer over snow. Am Meteorol Soc 44:912-1939

Auer AH (1981) Urban boundary layer. In: Changnon SA (ed) Metromex: a review and summary. American Meteorological Society, Boston, pp 41-62

Batchvarova E, Gryning S-E (2005) Progress in urban dispersion studies. Theor Appl Climatol 84:57-67. https://doi.org/10.1007/ s00704-005-0144-1

Blocken B, Stathopoulos T, Saathoff P, Wang X (2008) Numerical evaluation of pollutant dispersion in the built environment: comparisons between models and experiments. J Wind Eng Ind Aerodyn 96:1817-1831. https://doi.org/10.1016/j.jweia.2008.02. 049

Carpentieri M (2012) Pollutant dispersion in the urban environment. Rev Environ Sci Biotechnol 12:5-8. https://doi.org/10.1007/ s11157-012-9305-8

Carpentieri M, Salizzoni P, Robins A, Soulhac L (2012) Evaluation of a neighbourhood scale, street network dispersion model through comparison with wind tunnel data. Environ Model Softw 37:110-124. https://doi.org/10.1016/j.envsoft.2012.03.009

Draxler RR (1986) Simulated And Observed Influence Of The Nocturnal Urban Heat Island On The Local Wind Field. J Climate Appl Meteor 25:1125-1133. https://doi.org/10.1175/ 1520-0450(1986)025\%3c1125:SAOIOT\%3e2.0.CO;2

El-Harbawi M (2013) Air quality modelling, simulation, and computational methods: a review. Environ Rev 21:149-179. https:// doi.org/10.1139/er-2012-0056

EPA (1995) User's guide for the industrial source complex dispersion models, Vol. II-description of model algorithms, EPA-454/B95th-003b edn. EPA, Research Triangle Park

EPA (1994) An evaluation of a solar radiation delta-T method for estimating Pasquill-Gifford (P-G) stability categories, EPA-454/ R-93-055. EPA, Research Triangle Park

EPA (2000) Meteorological monitoring guidance for regulatory modeling applications EPA-454/R-99-005. EPA, Research Triangle Park

EPA (2004) User's guide for the aermod meteorological preprocessor (AERMET). EPA, North Carolina

EPA (2015) Industrial Source Complex ISC3. http://www.epa.gov/ $\mathrm{ttn} / \mathrm{scram} /$ dispersion_alt.htm\#isc3. Accessed 4 Aug 2015

Garstang M, Tyson PD, Emmitt GD (1975) The structure of heat Islands. Rev Geophys 13:139. https://doi.org/10.1029/ RG013i001p00139

Glazier J, Monteith JL, Unsworth MH (1976) Effects of aerosol on the local heat budget of the lower atmosphere. QJR Meteorol Soc 102:95-102. https://doi.org/10.1002/qj.49710243108

Godowitch JM, Ching JKS, Clarke JF (1985) Evolution of the nocturnal inversion layer at an urban and nonurban location. J Climate Appl Meteor 24:791-804. https://doi.org/10.1175/ 1520-0450(1985)024\%3c0791:EOTNIL\%3e2.0.CO;2

Gousseau P, Blocken B, van Heijst GJF (2011) CFD simulation of pollutant dispersion around isolated buildings: on the role of convective and turbulent mass fluxes in the prediction accuracy.
J Hazard Mater 194:422-434. https://doi.org/10.1016/j.jhazmat. 2011.08.008

Gryning S-E, Batchvarova E (2007) Chapter 1.2 Turbulence, atmospheric dispersion and mixing height in the urban area, recent experimental findings. In: Renner CB (ed) Developments in environmental science. Elsevier, New York, pp 12-20

Hanna S, Baja E (2009) A simple urban dispersion model tested with tracer data from Oklahoma City and Manhattan. Atmos Environ 43:778-786. https://doi.org/10.1016/j.atmosenv.2008.11.005

Hildebrand PH, Ackerman B (1984) Urban effects on the convective boundary layer. J Atmos Sci 41:76-91. https://doi.org/10.1175/ 1520-0469(1984)041\%3c0076:UEOTCB\%3e2.0.CO;2

Högström U, Bergström H, Alexandersson H (1982) Turbulence characteristics in a near neutrally stratified urban atmosphere. Bound-Layer Meteorol 23:449-472

Huq P, Franzese P (2012) Measurements of turbulence and dispersion in three idealized urban canopies with different aspect ratios and comparisons with a Gaussian plume model. Boundary-Layer Meteorol 147:103-121. https://doi.org/10.1007/s10546-0129780-z

Irwin JS, Carruthers D, Paumier J, Stocker J (2002) Assessing dispersion model performance to simulate average centerline concentration values. In: 12th Joint Conference on the Applications of Air Pollution Meteorology with the Air and Waste Management Association, https://ams.confex.com/ams/pdfpa pers/39297.pdf

José RS, Pérez JL, González RM (2004) Operational and forecasting real-time air quality tool for industrial plants. International Environmental Modelling and Software Societey, Osnabrueck

Landsberg H (1981) The Urban climate, 1st Edition. International Geophysics Series, vol. 28

Lateb M, Masson C, Stathopoulos T, Bédard C (2010) Numerical simulation of pollutant dispersion around a building complex. Build Environ 45:1788-1798. https://doi.org/10.1016/j.buildenv. 2010.02.006

Li W, Hiyama T, Kobayashi N (2007) Turbulence spectra in the nearneutral surface layer over the Loess Plateau in China. BoundLayer Meteorol 124:449-463

Madany A (1996) Fizyka atmosfery—wybrane zagadnienia. Oficyna Wydawnicza PW, Warszawa

McNaughton KG, Laubacg J (2000) Power spectra and cospectra for wind and scalars in a disturbed surface layer at the base of an advective inversion. Bound-Layer Meteorol 96:143-185

Mirzaei PA, Carmeliet J (2013) Dynamical computational fluid dynamics modeling of the stochastic wind for application of urban studies. Build Environ 70:161-170. https://doi.org/10. 1016/j.buildenv.2013.08.014

Moussiopoulos N (1997) Air pollution models and their role in environmental policy. In: Varotsos C (ed) Atmospheric ozone dynamics. Springer, Berlin, pp 241-250

National Research Council (1977) Energy and Climate Studies in Geophysics The Effect of Localized Man-Made Heat and Moisture Sources in Mesoscale Weather Modification. The National Academies Press, Washington, D.C.

Oke TR (1981) Canyon geometry and the nocturnal urban heat island: comparison of scale model and field observations. J Climatol 1:237-254. https://doi.org/10.1002/joc.3370010304

Oke TR (1995) The heat island of the urban boundary layer: characteristics, causes and effects. In: Cermak JE, Davenport AG, Plate EJ, Viegas DX (eds) Wind climate in cities. Springer, Netherlands, pp 81-107

Paine RJ, Egan BA (1987) User's guide to the rough terrain diffusion model (RTDM) (Rev. 3.20)

Panofsky HA, Tennekes H, Lenschow DH, Wyngaard JC (1977) The characteristics of turbulent velocity components in the surface 
layer under convective conditions. Bound-Layer Meteorol 11:355-361

Panofsky HA, Larko D, Lipschutz R et al (1982) Spectra of velocity components over complex terrain. Q J R Meteorol Soc 108:215-230

Polish Ministry of Environment (2010) Rozporzaddzenie ministra środowiska z dnia 26 stycznia 2010 r. w sprawie wartości odniesienia dla niektórych substancji w powietrzu

Saha K (2008) The earth's atmosphere its physics and dynamics. Springer, Heidelberg

Schulman L, Scire JS (1980) Buoyant line and point source (BLP) dispersion model user's guide. Environ Res Technol, Concord

Smedman-Högström A-S, Högström U (1978) A practical method for determining wind frequency distributions for the lowest $200 \mathrm{~m}$ from routine meteorological data. J Appl Meteorol 17:942-954. https://doi.org/10.1175/1520-0450(1978)017\%3c0942: APMFDW\%3e2.0.CO;2

Smeets CJPP, Duynkerke PG, Vugts HF (1998) Turbulence characteristics of the stable boundary layer over a mid-latitude glacier. Part I: a combination of katabatic and large-scale forcing. Bound Layer Meteorol 87:117-145

Tapper NJ (1990) Urban influences on boundary layer temperature and humidity: results from Christchurch, New Zealand. Atmos Environ Part B Urban Atmos 24:19-27. https://doi.org/10.1016/ 0957-1272(90)90005-F

Turner DB (1994) Workbook of atmospheric dispersion estimates. Lewis Publishers, Boca Raton

Uno I, Wakamatsu S, Ueda H, Nakamura A (1992) Observed structure of the nocturnal urban boundary layer and its evolution into a convective mixed layer. Atmos Environ Part B Urban
Atmos 26:45-57. https://doi.org/10.1016/0957-1272(92)90036$\mathrm{R}$

Walter RK, Nidzieko NJ, Monismith SG (2011) Similarity scaling of turbulence spectra and cospectra in a shallow tidal flow. J Geophys Res 116:2156-2202. https://doi.org/10.1029/ 2011JC007144

Wang F, Li J, Martinez-Piedra G, Korotkova O (2017a) Propagation dynamics of partially coherent crescent-like optical beams in free space and turbulent atmosphere. Opt Express 25(21):26055-26066

Wang F, Li J, Martinez-Piedra G, Korotkova O (2017b) Measuring anisotropy ellipse of atmospheric turbulence by intensity correlations of laser light. Opt Lett 42(6):1129-1132. https://doi.org/ 10.1364/OL.42.001129

Xie Z-T, Hayden P, Wood CR (2013) Large-eddy simulation of approaching-flow stratification on dispersion over arrays of buildings. Atmos Environ 71:64-74. https://doi.org/10.1016/j. atmosenv.2013.01.054

Zaïdi H, Dupont E, Milliez M et al (2014) Effect of atmospheric stability on the atmospheric dispersion conditions over a industrial site surrounded by forests. In: Steyn DG, Builtjes PJH, Timmermans RMA (eds) Air pollution modeling and its application XXII. Springer, Netherlands, pp 733-737

Zanetti P (1990) Air pollution modelling: theories, computational methods and available software. Van Nostrand-Reinhold, New York

Żeliński J, Kaleta D, Telenga-Kopyczyńska J (2016) Empirical estimation of virtual point source height over a Bank of Coke Ovens. Environ Model Assess 22:17-26. https://doi.org/10.1007/ s10666-016-9514-6 